\title{
Approaching a neoclassical scenario: the labor market in China after the Lewis turning point
}

Fang Cai

Correspondence:

caifang@cass.org.cn

Institute of Population and Labor

Economics, Chinese Academy of

Social Sciences, Beijing 100732,

China

\begin{abstract}
As China passes through its Lewis turning point characterized first by the appearance of a labor shortage and a constant increase in wages, its labor market shows both features of the dual economy and neoclassical growth. This paper first depicts the trend of population as a root cause of the labor market transition from dual economy to neoclassical scenario. It then reveals the changed labor market profile - the labor shortage and wage increase. By examining three major groups of employment, namely, migrant workers, university graduates, and urban vulnerable workers, it tries to explore those unique characteristics of the labor market in such a transitional period and draws policy implications.
\end{abstract}

Keywords: Demographic transition; Lewis turning point; Labor market institutions

\section{Introduction}

The three chief characteristics of a neoclassical scenario of the labor market, which I contrast with a dualistic scenario of the labor market such as described by Lewis (1954), are (1) wage is determined by marginal productivity of labor, (2) the labor market can correct its own disequilibrium in labor supply and demand over the long run, and (3) there are only three basic types of unemployment - cyclical, frictional, and structural - all of which need to be addressed with macroeconomic and labor market policies.

For some time, the Chinese economy has exemplified a dual economy characterized by unlimited labor supply, subsistence wages, and the existence of institutional barriers to labor mobility, as well as the resultant difficulty in labor market clearing. Consequently, employment issues in China were understood exclusively in Lewisian, and never in neoclassical terms. Since the implementation of reform and opening, and in particular China's entry into the WTO in the new millennium, an enormous number of surplus laborers from rural areas have migrated to coastal cities to take up nonagricultural jobs. It was not until very recently that the Lewis turning point arrived, signaled by widespread labor shortage and constant wage increases, particularly for unskilled workers, and facilitated by both demand and supply factors, such as demographic trends and strong growth of employment in urban areas.

While China is moving away from an unlimited supply of labor and toward a neoclassical labor market scenario, today's employment problems show both neoclassical and dual economy characteristics. Some of the more prominent of these problems are (1) underemployment in the agricultural sectors has yet to be alleviated, (2) the

(c) 2013 Cai; licensee Springer. This is an Open Access article distributed under the terms of the Creative Commons Attribution License (http://creativecommons.org/licenses/by/2.0), which permits unrestricted use, distribution, and reproduction in any medium, provided the original work is properly cited. 
worsening of cyclical unemployment, especially among migrant workers, (3) a higher degree of vulnerability among young people and older workers in urban areas than other groups to forms of natural unemployment, including structural and frictional unemployment, and (4) inadequate protection for workers' rights, including those relating to wage negotiation and labor disputes.

This paper illustrates how China's recent demographic trends, together with fast economic growth and employment expansion, have reshaped the country's employment landscape, which is characterized no longer by unlimited supply but by a nearequilibrium one. In response to this shift, we must also fundamentally change the way we understand China's employment problems and the challenges policy-makers face. In addition to promoting employment, increasingly, policies must try to address problems of cyclical and natural unemployment, particularly among those who have been hardest hit by the transition and as such are especially vulnerable.

In this paper we highlight key employment issues in China by looking closely at three distinct groups: migrant workers, college graduates, and the urban working vulnerable. Each of these groups faces its own set of employment-related difficulties. Migrant workers are prone to be affected by cyclical unemployment because when the urban labor markets tighten due to economic slowdowns, many of them end up returning to agriculture work, which is a form of underemployment. College graduates are most vulnerable to structural and frictional unemployment, which partly explains why unemployment rates are often higher among this group than among some other groups. Thirdly, the vulnerability of vulnerable workers in urban areas is due largely to inadequate education and skill, a situation for which there are deep historical reasons.

This last problem points toward major challenges in institution building, and we will discuss it in some detail in this paper. As a result of the widespread awakening to their rights and entitlements among ordinary workers, brought about by the arrival of the Lewis turning point and the continuing stress the labor market is under, labor disputes have been on the rise. The government has been quick to respond to this trend by passing legislations and implementing policies. This is in fact yet another sign that China's labor market is on track to turn from Lewisian, where it has been to some time, to neoclassical.

\section{The demographic trend and its impacts on labor supply}

Thanks to its strict implementation of the one-child policy, China has been able to complete in a very short time a demographic transition that took most developed countries much longer to complete. Since reform began, China's demographic profile has gone through the following stages: a sharp decline in fertility rate, then in the number of young people as a percentage of the total population, a decreasing growth rate for people of working age, and then the rapid aging of the Chinese population. When the percentage of young people contracted at a higher rate than the growth rate of the percentage of elderly people, China began to see a sufficient labor supply, a result of productive population structure. As these demographic trends continue, the working age population will grow more slowly, while the aging process will pick up speed. These trends will surely raise many challenges.

Despite the dramatic decline in the total fertility rate (TFR) in China throughout the 1970 s from 5.8 to 2.3 , by the early 1980 s, China's TFR was still above the replacement 
level. The drastic reduction in the fertility rate that China has been able to achieve owes very much to socioeconomic development on one hand and wide adoption of family planning on the other during the reform period. These circumstances were highly effective in arresting high fertility rates. By the dawn of the twenty-first century, not only had China successfully carried out the transition toward a modern population growth pattern, but it was also able to be in less than 30 years. By comparison, it took many industrialized countries of comparable income levels almost a century to do the same.

There have long been disagreements among scholars and official authorities about China's TFR. Figure 1 shows China's TFR from 1950 to 2009. All of the pre-1998 figures had government sources and were as such 'official', but scholars treat only those for the years after 1998 to be genuinely trustworthy. In Figure 1, one can see that the TFR in China has been below 1.5 for many years, which is quite low by international comparison (Gu and Li 2010).

As the Chinese government gradually began to distance itself from this position, i.e., that TFR in China has been below 1.5 for many years according to census data from the National Bureau of Statistics, the United Nations put China's TFR for 2006 at 1.4 in its newly published World Fertility Pattern, 2009, thereby placing the country among those with low fertility rates (United Nations 2010). We may yet be hit by a consequent decline in labor supply, which will happen quite unannounced.

One repercussion of persistently low fertility rates is a change in the age composition of a population. Since about 1980, the growth of the elderly population has accelerated, while that of the population of people of working age has decelerated, and the population of young people has shrunk altogether. We can conclude that under the condition of persistently low fertility rates, the growth of the working age population will slow before stopping altogether. These trends will eventually lead to labor shortages. According to one forecast based on the latest available statistics (United Nations Department of Economic and Social Affairs, Population Division 2011), the number of

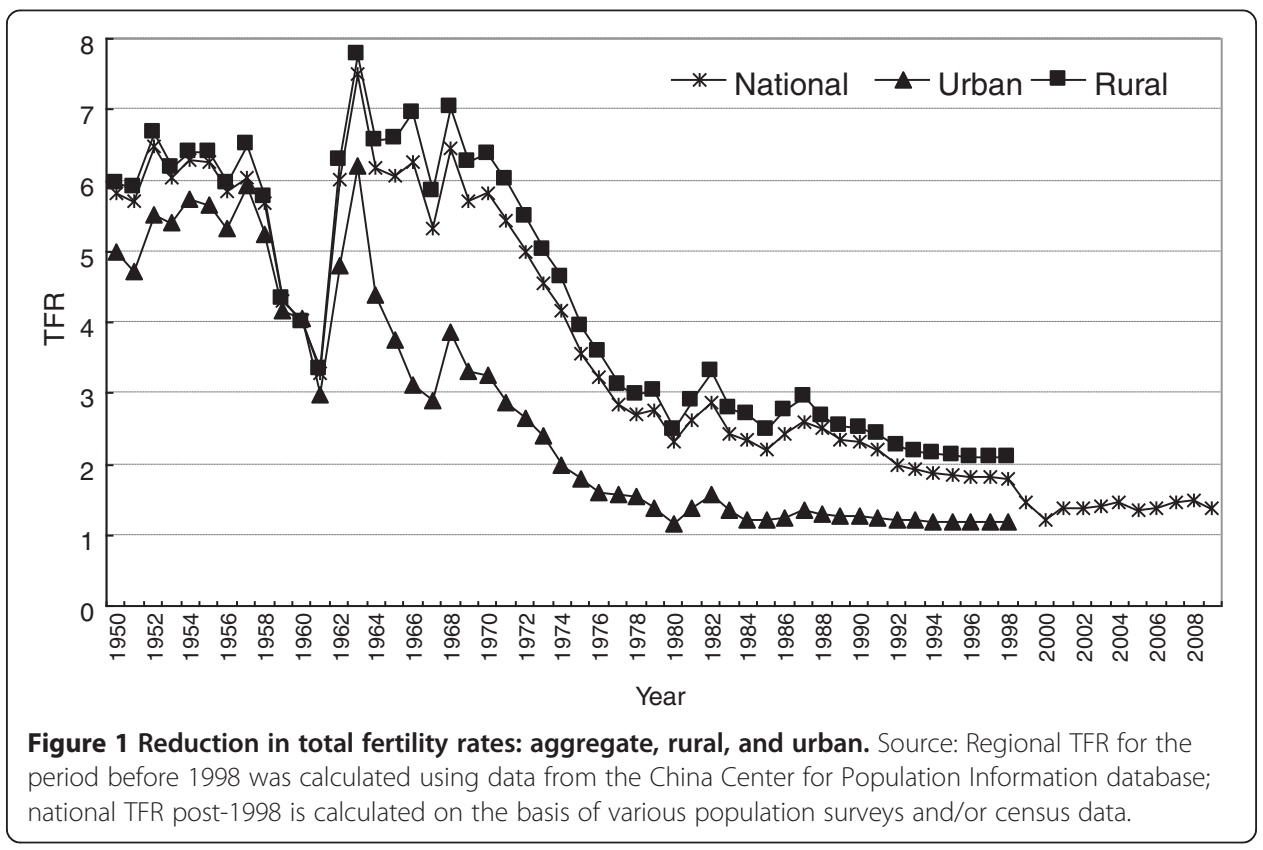


Chinese between the ages of 15 and 64 will peak in 2015, after which it will begin to decrease (Figure 2).

Trends such as those just described will lead to concomitant changes to the age structure of China's population. Our argument is based on two assumptions. First, we assume continual rise in enrollment in higher education and have left those aged 15 to 19 outside the purview of these analyses. Second, we assume that there will be little or no increase in the rate of labor force participation for people 65 or older and have included in our analysis only people between the ages of 20 and 64. In the next decade, we expect to see a rise in the average age of people of working age, a slight decrease in the population size of the very young, a more significant decrease in the population size of people of ages between those of the previous two groups, and the elderly to account for $32 \%$ of the nation's total population by 2020 .

As many previous studies have shown, among rural laborers, those with a more favorable demographic profile, e.g., those who are better educated and younger, are more likely to migrate and to settle in places farther from home and for longer periods ( $\mathrm{Du}$ and Wang 2010). Since non-agricultural labor supply is closely linked to rural-urban labor migration, and except in cases where sufficiently strong incentives intrinsic to the labor market or the prospects for professional growth exist, people of working age tend to become less mobile as they get older. Moreover, since older urban workers tend to face greater risks for structural and frictional unemployment, and the enrollment rate in higher education has continued to rise, an older labor force also means a reduction in labor force participation rates.

\section{Consequences for the labor market}

An aging population presents two huge challenges to any society. On one hand, it poses a threat to the sustainability of the pension system and elderly care infrastructure, and on the other hand, it reduces labor supply. In the period of reform, when there existed underemployment in both rural and urban sectors, the Chinese government has actively helped promote employment by developing the labor market and reallocating

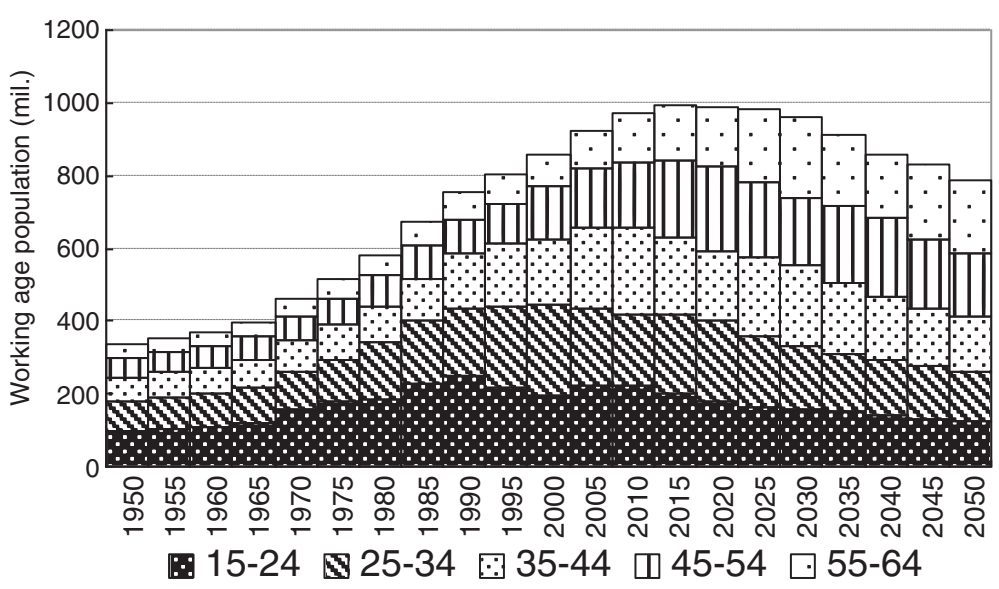

Figure 2 Changing age composition of working age population. Source: United Nations Department of Economic and Social Affairs, Population Division (2011). 
people among different sectors and between rural and urban areas. Therefore, China's economic growth is on one hand partly attributable to the massive supply of labor and on the other the reallocative efficiency gained by labor mobility from agricultural to non-agricultural sectors, which constitutes the demographic dividend of total factor productivity growth (World Bank 1997; Cai and Wang 1999, 2005). As China enters a new demographic era, the impact on the labor market will be enormous. These changes will shape the course of China's future development.

\section{Labor supply and demand: basic characteristics}

Even though past forecasts for the annual increase in the number of new entrants to the nation's workforce never put the number above 20 million, official figures for the number of new jobs needed each year to absorb the addition workers have been consistently larger. According to calculations from the Ministry of Human Resources and Social Security, there are a total of more than 24 million people in the labor reserve. They arrive at this number by adding up the numbers for three groups of people: more than ten million new entrants to the labor market, each year; more than eight million people currently unemployed who are looking for work; and over six million laid-off workers who need work (Zhang 2008).

This calculation method is problematic, however. First of all, it is missing a temporal dimension and creates the false impression of timelessness. While the landscape of China's labor demand and supply has changed significantly in recent years, some of the basic categories assumed in this calculation no longer exist. For example, what used to be called 'laid-off workers' were renamed in 2005 and are now referred to as the 'registered unemployed'. This means that, at least officially, there were no longer any laid-off workers in China but a total of 80 million registered unemployed in 2008. The second problem with this calculation is that it is based on the questionable assumption that all of the unemployed must be absorbed. But this intention is neither necessary nor feasible. According to mainstream theories of employment, insofar as there is such a thing as natural unemployment rate, it tends to stay fairly stable over the long run.

The demographic and economic trends described above have led to a changed relationship between labor supply and demand. Take the annual increase in the number of people between the ages of 16 and 64 on the supply side and the annual increase in the number of urban workers on the demand side. When the two trends are examined together, the changing dynamics of the labor market become obvious. Since the number of agricultural workers has been falling while that of non-agricultural workers in rural areas is not expected to expand, we may treat the increases in the number of urban workers, migrant workers included, as representative of the magnitude of the overall labor demand of the Chinese economy.

In what follows, we take a closer look at the general employment situation in China by comparing the demand and the supply of labor for urban sectors. There are two parts to the statistical data on urban employment in China. The first includes the total number of urban employees, which is published by the National Bureau of Statistics (NBS). This number does not, however, cover most migrant workers in urban areas. According to estimation on the basis of microdata from 2009, only $12.5 \%$ of the total of 310 million urban employees were migrant workers. The second part includes the total 
number of people classifiable as migrant workers according to the NBS official definition. According to that definition, an individual qualifies as a 'migrant worker' if s/he has been away from the town or township of their household registration for 6 months or more. Surveys have shown that of all migrant workers, 95.6\% work and live in cities of varying sizes. Factoring in the overlap between these two numbers, we can calculate the actual number of urban workers inclusive of both registered urban residents and migrant workers. We can then compare this number with the total number of people of working age in the country (Table 1 ).

Between 2001 and 2011, labor demand of urban sectors, which encompasses employment among both urban residents and the migrants, grew at an annual rate of $3.2 \%$. During the same period, labor supply, measured by the number of people of working age, grew by an annual rate of only $1.1 \%$. For the purpose of this study, we have excluded people older than 60 from working age population because, given China's retirement age - 60 for men and 55 for women - they by default stand little chance of finding a job in the present labor market. A look at people between the ages of 15 and 59 shows that this population had begun to shrink by 2010. This suggests, among other things, that the problem of high rates of underemployment in both the rural and the urban labor markets was finally easing. As such, constant surplus of supply relative to demand no longer accurately describes China's labor market after the arrival of the Lewis turning point.

\section{Wage increases for unskilled workers}

Wages have been growing continuously in China since the late 1990s, when a huge number of workers were laid off in urban areas and labor productivity increased as a consequence. Since the beginning of this century, the average wage in major urban sectors has been rising at an annual rate of over $8 \%$, which is unrivaled by any group anywhere in the world. However, understanding China's official statistical data on wages can be a challenge because of the complex ways in which they are collected and calculated. For example, data on urban wage cover only workers formally employed in

Table 1 Increases in demand for and supply of labor force (million, \%)

\begin{tabular}{|c|c|c|c|c|c|c|}
\hline & \multicolumn{2}{|c|}{ Urban resident workers } & \multicolumn{2}{|c|}{ Migrant workers } & \multicolumn{2}{|c|}{ Working age population } \\
\hline & Numbers & Growth rate & Numbers & Growth rate & Numbers & Growth rate \\
\hline 2001 & 236 & - & 80 & - & 885 & - \\
\hline 2002 & 241 & 2.1 & 100 & 24.7 & 901 & 1.7 \\
\hline 2003 & 246 & 2.0 & 109 & 8.8 & 914 & 1.5 \\
\hline 2004 & 250 & 1.8 & 113 & 3.8 & 929 & 1.6 \\
\hline 2005 & 254 & 1.7 & 120 & 6.4 & 944 & 1.6 \\
\hline 2006 & 259 & 2.0 & 126 & 5.0 & 952 & 0.9 \\
\hline 2007 & 265 & 2.1 & 131 & 3.7 & 960 & 0.8 \\
\hline 2008 & 268 & 1.3 & 134 & 2.5 & 968 & 0.8 \\
\hline 2009 & 272 & 1.4 & 139 & 3.5 & 974 & 0.7 \\
\hline 2010 & 277 & 1.6 & 146 & 5.3 & 981 & 0.7 \\
\hline 2011 & 280 & 1.0 & 152 & 3.7 & 986 & 0.6 \\
\hline
\end{tabular}

Source: Authors' own calculations based on China Statistical Yearbook (various years), China Yearbook of Rural Household Survey (various years), and China Population Yearbook (various years), and Du and Hu (unpublished memo). 
formal sectors and leave out information on temporary workers and those who work in informal sectors; therefore, such data cannot be relied upon completely if one wants to understand the dynamics of the situation in China with respect to wages. However, wage increases for migrant workers warrant close examination since they not only make up one third of urban employment but also account for a large percentage of informal workers in non-agricultural sectors,

Until 2004, wages for migrant workers had shown little growth even though wages for urban workers who are local residents had begun to rise. In 2004, the country was hit by the first migrant labor shortage, which triggered a rapid increase in wages. As can be seen in Figure 3, wages for all sectors, including those dominated by migrant workers (such as manufacturing and construction), have been increasing constantly, while the wage increase for migrant workers has been particularly impressive. We conclude, therefore, that observed wage increases are mainly attributable to changes in labor demand and supply. We have included here the figures for wage increases in select agricultural sectors as further evidence for the validity of this claim. Indeed, strong wage growth in agricultural sectors signals the decline of the dual economy, which, according to Lewis, is an economy characterized by surplus labor in agriculture.

Wages for migrant workers have been rising continuously since 2004, as a result of migrant labor shortages. Even the global financial crisis did not interrupt this trend. A survey done by the NBS shows that the average real monthly wage of migrant workers was 1,221 yuan in 2009 , which was $90 \%$ higher than what it was in 2001 . The real wage of migrant workers increased by $19 \%$ in 2010 and further increased by $21 \%$ in 2011 . Other surveys and reports besides the one by NBS have put the figures for migrant labor wage increases even higher. For example, according to a survey conducted in early 2010 by the People's Bank of China, China's central bank, the average wage for migrant workers was 1,783.2 yuan in 2009, 17.8\% higher than the year before (Department of Survey and Statistics, People's Bank of China (DSS-PBC) 2010).

In fact, because urban local workers and migrant workers tend to differ considerably with respect to their hours and pay structures, a comparative analysis of the wages for

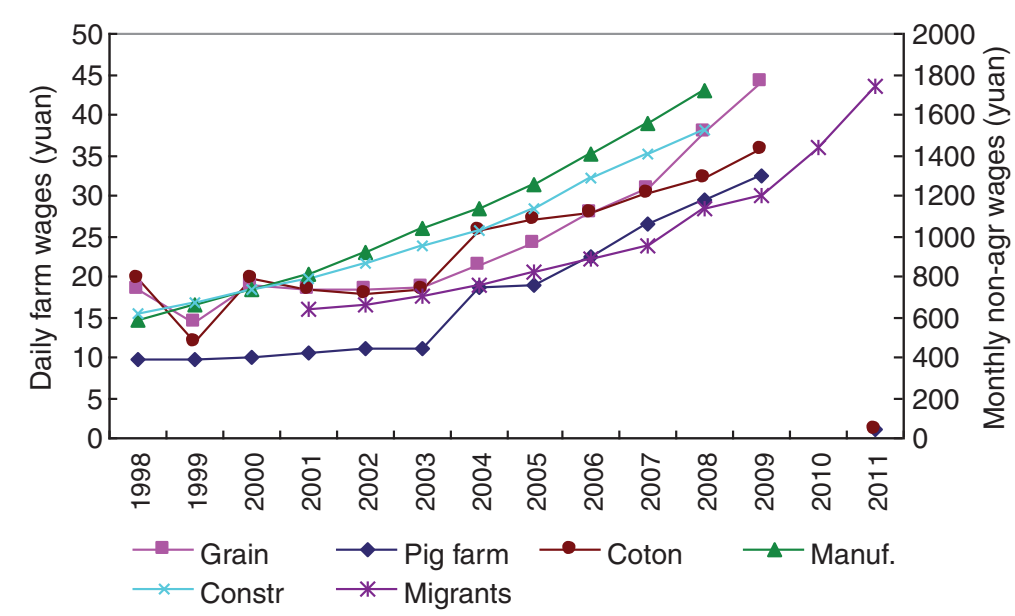

Figure 3 Wage increases in select sectors. Source: Data on the daily wages for workers in grain and cotton production and on hog farms with more than 50 hogs are from Compilation of national farm product cost-benefit data, monthly wages of manufacturing and construction are from China Labor Statistics (various years), and monthly wages of migrant workers are from NBS Statistical Report (various years). 
the two groups must factor in both wage rates and working hours. According to a 2010 survey ('China Urban Labor Survey' or CULS a), migrant workers work for an average of $27 \%$ longer than do urban local workers per week, and their hourly wage rates were on average $88.2 \%$ of the average wage rate for local urban workers. This means that the reason the average monthly earning for migrant workers was higher (by $5.6 \%$ higher) than the number for urban local workers was that the former make up for lower hourly wage rates with longer hours worked.

Moreover, as the demographic profile of this population evolves, so do working habits. For example, younger workers today tend to work fewer hours than their older counterparts used to previously. Findings from CULS show that in 2010, migrant workers worked an average of almost $12.4 \mathrm{~h}$ less than did migrant workers in 2005. This means that the increase in total monthly earning for migrant workers is a reflection of substantial surge in wage rate (i.e., hourly rate).

\section{Rise in labor disputes}

In recent years, particularly after 2008, the year in which several labor-related laws were passed or updated, heightening workers' awareness of rights and entitlements ${ }^{\mathrm{b}}$, the incidence of labor disputes in China has increased sharply. According to official records, the total number of labor disputes in 2010 was twice what it was in 2003. Moreover, the number of incidents of severe unrest triggered by conflicts in labor relations has grown too. That is not necessarily a sign of worsening trend in labor relations, but may be more of an indication of stronger demand for labor market institutions.

In his seminal work, Hirschman (1970) named three mechanisms, namely, exit, voice, and loyalty, by which citizens, consumers, and workers can express their dissatisfaction with conditions in the market. Here, we borrow those expressions to describe changed labor relations in China after the arrival of the Lewis turning point. As laborers in general and migrant workers in particular (especially in China) enjoy more employment opportunities, there has also been greater room for them to exercise their rights by 'voting with their feet', i.e., by choosing 'exit' .

How individual migrant workers use their power of choice depends on what jobs they hold. For example, workers who are dissatisfied with their jobs in small companies with poor growth prospects may simply quit since the odds are fairly good that they can find a better job elsewhere. But for workers who are dissatisfied with but reluctant to leave their jobs in sizable companies with some industry recognition and growth potential, efforts to seek higher pay and better working conditions may take the form of overt actions such as vocal complaints, collective bargaining, and, in more extreme cases, strikes.

Figure 4 shows the level of labor dispute in different provinces such as measured by the ratio between the number of reported cases and total employment. We can see that they happen more often in the more developed coastal regions than they do elsewhere. Of the total number of labor disputes in China in 2008, a vast majority, or $74.8 \%$, took place in eastern provinces.

There are several reasons for these regional variations in the occurrence of labor disputes. They are (1) the Lewis turning point came to the more developed region earlier than it did elsewhere, (2) the more developed region is also where migrant workers are most concentrated $^{\mathrm{c}}$, and (3) since migrant workers are more vulnerable to abuse, they 


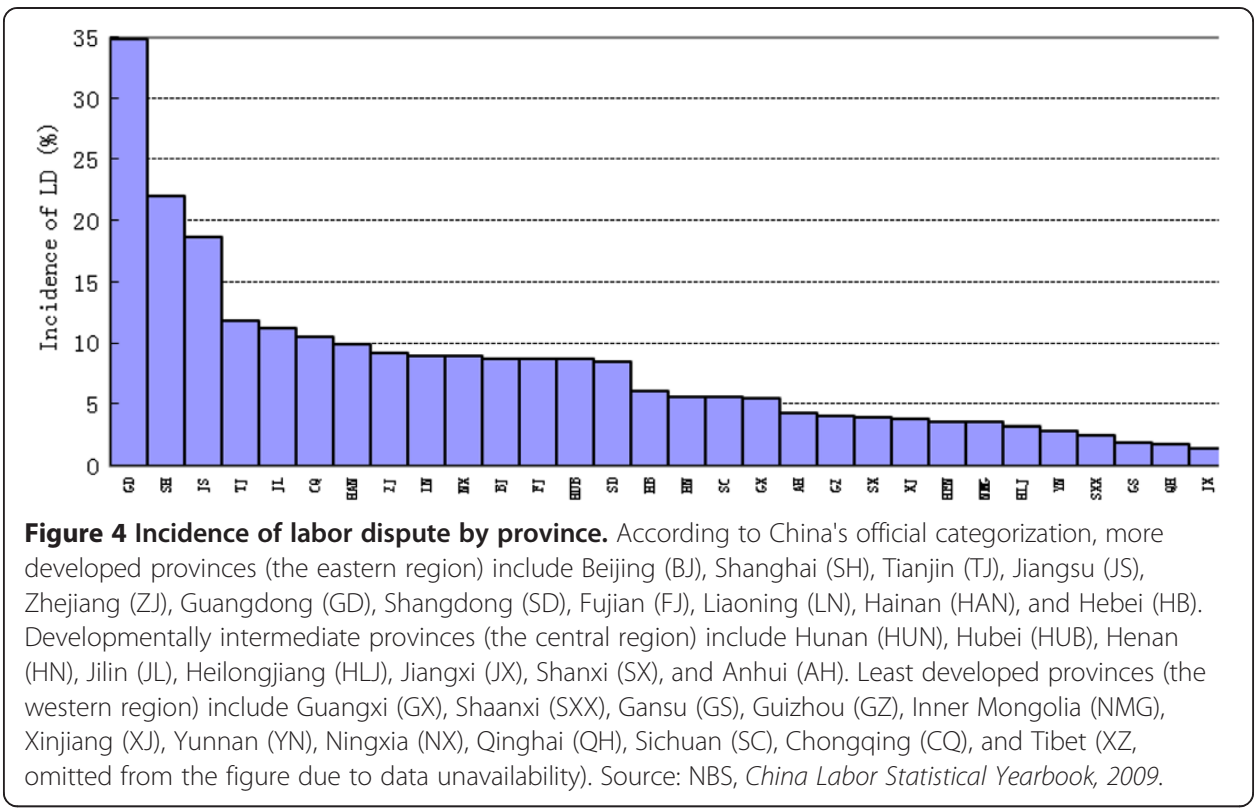

are correspondently more likely to initiate actions in defense of their rights. The rise in labor disputes and the uneven geographical distribution of their occurrence both suggest that there has been a sharp increase both in worker awareness about rights and in the demand for the institutionalization of their protection.

\section{Three vulnerable groups}

In studying unemployment, scholars in macroeconomics and labor economics have mostly focused on two types of unemployment: cyclical unemployment and natural unemployment (which includes frictional and structural unemployment). In a typical labor market and under normal conditions, macroeconomic fluctuations are associated with temporary changes in the relationship between labor demand and supply, which generate cyclical unemployment. By contrast, natural unemployment, either in the form of frictional or structural employment, is the effect of a mismatch between the employment objectives of workers on one hand and employment opportunities employers can offer on the other. More specifically, such a mismatch can reflect either the time cost of job search or changes in skill requirements.

As market mechanism plays an increasingly prominent role in labor allocation and macroeconomic business cycles occur in China, both cyclical and natural unemployment have been present. According to one estimate (Cai et al. 2004), during the period between 1995 and 2002, roughly 60\% to 80\% of urban unemployment in China that had been observed was not the result of macroeconomic fluctuations and should be classified as natural unemployment.

According to Lewis (1954), as a dual economy grows, excess labor supply in agriculture is increasingly absorbed by expanding non-agricultural sectors. It is widely believed that $30 \%$ to $40 \%$ of China's agricultural labor force during the period between the mid1980s and the late 1990s constituted excess supply (Taylor 1993; Carter et al. 1996). Similarly, as a legacy of a planned economy, $30 \%$ to $40 \%$ of total employees of state- 
owned enterprises (SOEs) in urban areas were deemed dispensable (Zhang 2008). Both of these forms of underemployment, affecting rural and urban sectors, respectively, are tantamount to a kind of hidden unemployment. We can distinguish, therefore, three different forms of unemployment: cyclical, natural (frictional and structural), and hidden, and discuss changes in them separately.

When economic reform began in China, the Chinese economy was a typical dual economy characterized by a sharp rural-urban dichotomy and high rates of hidden unemployment in both spheres. At the same time, both natural unemployment and cyclical unemployment have existed in China. The former is due to a combination of pervasive underdevelopment, inadequate public employment services, and the prevalence of mismatch between job skills and requirements. The latter is due to macroeconomic fluctuations, which happened throughout the reform period. In order to be able to focus our analytical attention on how the transition away from a dual economy reduced hidden unemployment, the effects of urban employment policy reform, and the breakup of the 'iron rice bowl' at SOEs, we shall assume that cyclical unemployment and natural unemployment stay relatively constant.

From Figure 5, a sketch map, one can see that since the beginning of China's reform policies, as the migration of surplus rural labor into urban areas and the reallocation of redundant urban workers continued, hidden unemployment shrank substantially in terms of both aggregate scale and percentage of total 'unemployment'. A number of empirical studies have shown that the massive flows of labor force from agricultural to non-agricultural sectors and from rural to urban areas have contributed tremendously to the reduction in the amount of excess labor in agriculture (for example, Cai and Wang 2008). Since 2004, when the first nationwide labor shortage took place, the wage rates for ordinary workers have been rising continuously. This was by definition a Lewis turning point.

The urban labor market has been experiencing painful adjustments since the late 1990s, and a total of 40 million workers were laid off up to 2002. As the economy continues to grow and the labor market to evolve, people who had been laid off and were officially registered as unemployed have either found new jobs or retired. It seems, therefore, that while these kinds of adjustments help eliminate hidden

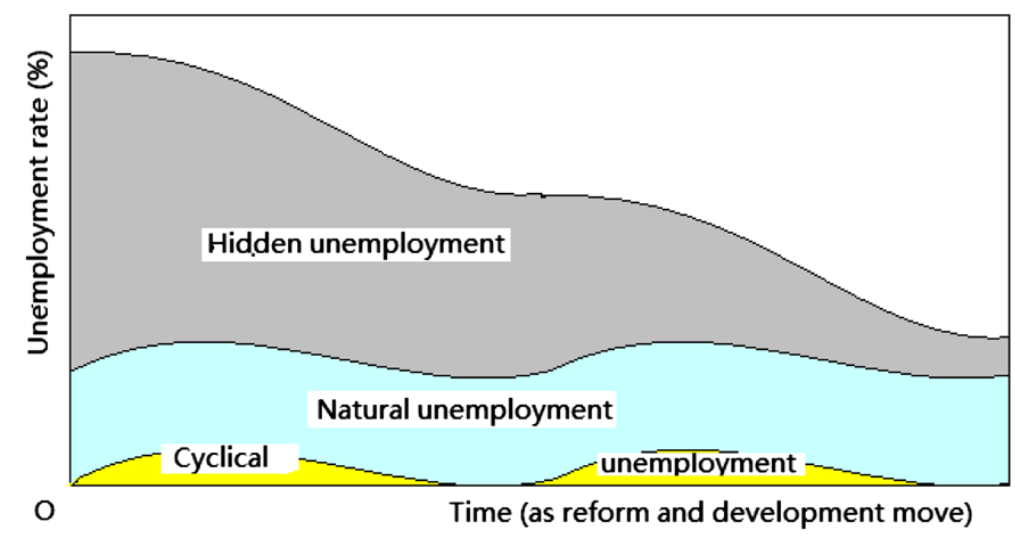

Figure 5 Unemployment types and their changing trends. 
unemployment in urban areas, older workers are more vulnerable to frictional and structural unemployment.

Both the government and the public recognize three subpopulations in China as being particularly vulnerable with respect to employment. These are migrant workers, college graduates, and urban vulnerable workers who are relatively old and poorly educated, who suffer from unemployment or difficulty of finding jobs from time to time. By taking a closer look at each of these groups, one can begin to understand better the new challenges China is facing in this transition toward a neoclassical labor market.

In Chinese, a migrant worker is, literally, a 'farmer turned worker'. Much of this population is made up of surplus labor from rural areas. One's status as a migrant worker does not necessarily mean that $\mathrm{s} / \mathrm{he}$ is unwanted for agricultural production. More often, agricultural workers who choose to migrate into the cities do so because they better satisfy the personal conditions for migration than others. In other words, in comparison with those who stay behind, rural migrants have some notable advantages.

First, a higher percentage of migrants, who are mostly between the ages of 20 and 30, would have had some formal education. Many would have completed 9 years of free education legally mandated in China. As such, this population is suitably prepared for most of the unskilled and/or semiskilled jobs available in urban areas. Second, because they invariably lack access to social protections, including employment assistance, they can ill afford to stay unemployed and have no income. As a result, they tend to have a higher level of tolerance for poor pay and poor working conditions and have a high rate of labor participation. Third, since this population tends to suffer from spatial distance between where they live and where they can find a job, institutional exclusion from decision-making, and informational asymmetry between them and their employers, they tend to be cut off to a certain extent from market demand.

Today, agriculture is no longer able to reabsorb migrant returnees from the cities when urban labor demand crashes during an economic downturn. There are two major reasons for this. First, agricultural production has changed greatly from what it was in earlier times, in part as a result of the great labor hemorrhage. Second, the demand for migrant workers in urban areas is now relatively inelastic. They are, therefore, no longer a reserve labor force but rather the pillar of the urban labor market. However, since they tend to receive weaker institutional protections and enjoy less of a social safety net, they are more likely to become victims of labor market volatility caused by macroeconomic fluctuations. As the macroeconomy goes through cycles of boom-and-bust, high rates of cyclical unemployment among migrant workers and migrant worker shortages take place alternately.

The difficulties in finding a job facing university graduates are a relatively new phenomenon. Before the massive expansion of university enrollment, university graduates were a scarce human resource and tended to be highly valued in the labor market. Even though the system of job placement had largely been phased out by the end of the 1990s, as a group, college graduates had relatively little difficulty securing jobs and the unemployment rate among them remained low. This began to change, however, when the first graduates from the classes of enlarged enrollment entered the labor market. In 2001, when this group of students was yet to graduate from universities, the share of new entrants in the total unemployed who used publicly run employment services was $16.5 \%$. By contrast, in 2002, when the graduates from the first class of 
enlarged enrollment who had spent 3 years or longer in colleges entered the labor market, that number increased to $20.1 \%$. In 2011 , it reached $23.9 \%$. Of these unemployed new entrants, 40.6\% were that year's university graduates. A 2005 national survey shows that the unemployment rate was $8 \%$ among 3 -year college graduates and $6.1 \%$ for university graduates. Both these numbers were significantly higher than the urban average of 5.2\% (Cai and Wang 2009; Wang and Cai 2009).

While the higher unemployment rate and the employment difficulties facing university graduates are no doubt in part caused by macroeconomic cycles of boom-and-bust, to a higher degree, they are a case of frictional and structural unemployment. As human capital, university graduates in general have a higher value than and are at an advantage relative to other groups, including migrant workers, (older) urban workers, and new entrants into the labor market with fewer years of formal education. They are, therefore, more likely to work in the formal sectors, to be better paid, and to enjoy more job security. However, since their training is more in specific skills than that of other groups, the job search for university graduates requires more time and a more sophisticated matching mechanism. As a result, they are more likely to face the risk of structural and frictional unemployment.

Among urban laborers, human capital deficiency is typically associated with older age, less formal education, poorer health, and outdated skills. This is another population that faces greater risks for natural unemployment. Let us consider the effect of education, for example. According to one study (Wang and Niu 2009), for those in the 24 to 64 age range, each additional year in age difference corresponds to a $10.2 \%$ drop in educational attainment. The correlation becomes more pronounced among older workers. For those in the 44 to 64 age range, each additional year in age difference represents a $16.1 \%$ reduction in the level of educational attainment. Suppose there is a critical minimum to human capital - say (and not unreasonably), 9 years of formal education, which is required for all Chinese citizens - the demarcation separating those who meet it and those who do not would be the age of $33^{\mathrm{d}}$.

Therefore, this group of laborers is subject not only to the risks of layoffs induced by the campaign to break the iron rice bowl of SOEs but also to the risks of frictional and structural unemployment. One silver lining for them, however, is that since most of them have urban hukou, or household registrations, and are already living in urban communities, they tend to be counted properly in official statistics in regard to their employment status. By contrast, migrant workers are often discounted, undercounted, or uncounted altogether. This is evidenced by the fact that they have consistently accounted for a large share of the registered unemployed in official records. On the one hand, since the difficulties those laborers face are long-standing and persistent, registered unemployment in urban areas has been relatively insensitive to macroeconomic fluctuations. But on the other hand, they are also relatively well protected by the urban social security system and safety net.

\section{Conclusions and policy implications}

Thanks to rapid economic growth, fundamental changes in society, and strict implementation of family planning policies since the early 1980s, China has achieved a population transition, changing from one characterized by 'high birth rate, low mortality 
rate, and high growth rate' to one of 'low birth rate, low mortality rate, and low growth rate', and has done so within a very short time. There have been a number of concomitant demographic changes, most notably with respect to age structure, which in particular has generated a demographic dividend during much of this period but that began to dissipate in the early twenty-first century. The labor market has responded to these developments, which can be clearly seen in the nationwide labor shortage and steep rises in worker wage.

According to the literature of development economics, these phenomena signal the arrival of the Lewis turning point. Since this point marks a separation between a dual economic labor market and a neoclassical one, China faces new and fundamentally different tasks and challenges in its effort to maintain good order in its labor market and to keep unemployment rates low. In particular, instead of focusing exclusively on promoting employment, employment policies in China should also address problems of cyclical and natural unemployment and in ways that uniquely suit the situation in China.

First, the household registration (or hukou) system, a unique institution that makes a sharp distinction between the rural and urban labor markets, is a key target for reform if China's labor market is to see greater development. More specifically, one important part of this reform is to allow migrants to apply to be granted urban resident status so they can have full access to social services. This can not only help keep the labor supply adequately large and stable but can also help reduce the negative effects of cyclical unemployment for migrant workers.

Second, education and training are areas in which more profound visions and more assertive government actions are urgently needed. In China, one serious problem is that wage convergence tends to generate a disincentive to complete schooling. To counter this tendency, heavier public spending toward education and better coordination between the education system and the labor market are imperative. Boosting labor force participation through, say, increasing the retirement age can only be effective if accompanied by systematic increases in continuing education and job training for older workers.

Third, the construction of labor market institutions is now of critical importance. Lessons from the experiences of either advanced countries or those of middle-income level suggest that labor market institutions, including industrial relations legislation, minimum wage regimes, laws governing collective bargaining, and unemployment protection, are instrumental for coordinating the demands of different groups and for maintaining social cohesion.

\section{Endnotes}

${ }^{a}$ China Urban Labor Survey or CULS is a series of surveys conducted by the Institute of Population and Labor Economics, Chinese Academy of Social Sciences in 2001, 2005, and 2010, respectively. It representatively sampled laborers in urban households and migrant households and surveyed both individual laborers and households in Shanghai, Wuhan, Shenyang, Fuzhou, and Xi'an.

bIn the year 2008 alone, three labor-related laws began implementation, of which the Employment Contract Law emphasizes on enhancing employment security and on 
providing better protection for migrant workers and the urban working vulnerable, the Employment Promotion Law clearly claims the responsibility of governments in promoting employment and in eliminating various kinds of labor market discrimination, and Labor Disputes Mediation and Arbitration Law is intended to provide a legal framework for improving labor relations.

${ }^{c}$ In 2004, for example, $70 \%$ of Chinese migrant workers were in the eastern region (Sheng and Peng 2006).

${ }^{d}$ The critical age here is estimated based on data of the country as a whole. Because the educational attainment level in rural areas is lower than that in urban areas, it may postpone a little bit if we examine the urban working age population. The conclusion holds unchanged - that is, the older the less educated and the critical point of 9 years of compulsory education arrives much before the official retirement age. For a related analysis on education attainments and returns to human capital in both rural and urban areas, see Wang (2009).

Competing interests

The author declares that he has no competing interests.

\section{Authors' information}

FC, born in 1956, graduated from Renmin University of China and Graduate School of Chinese Academy of Social Sciences (CASS). He holds a Ph. D. degree in economics. Currently, he serves as a Member of the Standing Committee and Agricultural and Rural Committee of the National People's Congress of China, a Fellow of the Chinese Academy of Social Sciences, and the Director of the Institute of Population and Labor Economics, CASS. He is also a Member of the Global Agenda Council on Ageing and a Member of the Population and the Planet Working Group, Royal Society. He published The Chinese Economy and The Lewis Turning Point, and he has been editing the Greenbook Series of Population and Labor.

Received: 5 January 2013 Accepted: 8 November 2013

Published: 13 December 2013

\section{References}

Cai F, Wang D (1999) The sustainability of China's economic growth and the contributions of labor. Econ Res J 10:62-68

Cai F, Wang D (2005) China's demographic transition: implications for growth. In: Garnaut R, Ligang S (ed) The China boom and its discontents. Asia Pacific Press, Canberra, pp 34-52

Cai F, Wang M (2008) A counterfactual analysis on unlimited surplus labor in rural China. China World Econ 16(1):51-65

Cai F, Wang M (2009) The Chinese employment situation and youth employment difficulties. In: Cai F (ed) The China population and labor yearbook. The sustainability of economic growth from the perspective of human resources, vol 10. Social Sciences Academic Press, Beijing, pp 27-43

Cai F, Du Y, Gao W (2004) Employment elasticity, NAIRU and macroeconomic policies. Econ Res J 39(9):5-18

Carter C, Zhong F, Cai F (1996) China's ongoing reform of agriculture. Institute, San Francisco

Department of Survey and Statistics, People's Bank of China (DSS-PBC) (2010) The fifth monitoring report on migrant workers. In: Cai F (ed) The China population and labor yearbook volume 11: labor market challenges in the post-crisis era. Social Sciences Academic Press, Beijing, pp 35-47

Du Y, Wang M (2010) New estimate of surplus rural labor force and its implications. J Guangzhou U (Soc Sci Edition) 9(4):17-24

Gu B, Li J (2010) The debate on China's population policy in the $21^{\text {st }}$ century. Social Sciences Academic Press, Beijing Hirschman A (1970) Exit, voice, and loyalty: responses to decline in firms, organizations, and states. Harvard University Press, Cambridge

Lewis A (1954) Economic development with unlimited supply of labor. Manch Sch 22:139-191

Sheng L, Peng $L$ (2006) Current situation of rural migrant laborers: quantity, components and individual characteristics. In: Cai F (ed) The China population and labor yearbook volume 7: demographic transition and its social and economic consequences. Social Sciences Academic Press, Beijing, pp 44-57

Taylor JR (1993) Rural employment trends and the legacy of surplus labor, 1978-1989. In: Kueh YY, Ash RF (ed) Economic trends in Chinese agriculture: the impact of post-Mao reforms. Oxford University Press, New York, p 352

United Nations (2010) World fertility patterns. http://www.un.org/esa/population/publications/worldfertility2009/ worldfertility2009.htm. Accessed 22 Dec 2011

United Nations Department of Economic and Social Affairs (2011) Population Division. World population prospects, The 2010 revision. CD-ROM Edition, 2011

Wang M (2009) Universal high school and mass higher education. In: Cai F (ed) The China population and labor yearbook volume 10: the sustainability of economic growth from the perspective of human resources. Social Sciences Academic Press, Beijing, pp 163-174 
Wang D, Cai F (2009) The education and employment of rural and urban youth in China. In: Cai F (ed) The China population and labor yearbook volume 10: the sustainability of economic growth from the perspective of human resources. Social Sciences Academic Press, Beijing, pp 44-64

Wang G, Niu J (2009) Composition and development of the Chinese education system. In: Cai F (ed) The China population and labor yearbook volume 10: the sustainability of economic growth from the perspective of human resources. Social Sciences Academic Press, Beijing, pp 104-123

World Bank (1997) China 2020: development challenges in the new century. World Bank, Washington, D.C

Zhang X (2008) The reforms and developments of the Chinese employment. China Labor and Social Security. Press, Beijing

doi:10.1186/2196-5633-1-1

Cite this article as: Cai: Approaching a neoclassical scenario: the labor market in China after the Lewis turning point. China Finance and Economic Review 2013 1:1.

Submit your manuscript to a SpringerOpen ${ }^{\circ}$ journal and benefit from:

- Convenient online submission

- Rigorous peer review

- Immediate publication on acceptance

- Open access: articles freely available online

- High visibility within the field

- Retaining the copyright to your article

Submit your next manuscript at $>$ springeropen.com 